\title{
(6) OPEN ACCESS \\ Management of children in the deployed intensive care unit at Camp Bastion, Afghanistan
}

\author{
David P Inwald, ${ }^{1}$ G S Arul, ${ }^{2}$ M Montgomery, ${ }^{2}$ J Henning, $^{3}$ J McNicholas, $^{4}$ S Bree $^{5}$
}

${ }^{1}$ Faculty of Medicine, Imperial College, Wright Fleming Institute, London, UK ${ }^{2}$ Birmingham Children's Hospital, Birmingham, UK ${ }^{3}$ Ministry of Defence Hospital, Unit Northallerton, The James Cook University Hospital, Middlesbrough, UK ${ }^{4}$ Ministry of Defence Hospital Unit Portsmouth, Queen Alexandra Hospital, Portsmouth, UK

${ }^{5}$ Ministry of Defence Hospital Unit Derriford, Derriford Hospital, Plymouth, UK

\section{Correspondence to} Maj David P Inwald, Section of Paediatrics, Faculty of Medicine, Imperial College, St Mary's Campus, Wright Fleming Institute, Norfolk Place, London W2 1PG, UK d.inwald@imperial.ac.uk

Received 5 September 2013 Revised 29 October 2013 Accepted 3 November 2013 Published Online First 4 December 2013
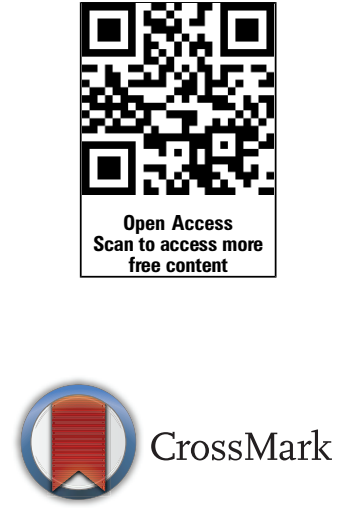

To cite: Inwald DP, Arul GS, Montgomery $\mathrm{M}$, et al. J R Army Med Corps

2014;160:236-240.

\section{ABSTRACT}

Background The deployed Intensive Therapy Unit (ITU) in the British military field hospital in Camp Bastion, Afghanistan, admits both adults and children. The purpose of this paper is to review the paediatric workload in the deployed ITU and to describe how the unit copes with the challenge of looking after critically injured and ill children.

Methods Retrospective review of patients $<16$ years of age admitted to the ITU in the British military field hospital in Camp Bastion, Afghanistan, over a 1-year period from April 2011 to April 2012.

Results $112 / 811(14 \%)$ admissions to the ITU were paediatric (median age 8 years, IQR 6-12, range 1-16). 80/112 were trauma admissions, 13 were burns, four were non-trauma admissions and 15 were readmissions. Mechanism of injury in trauma was blunt in 12, blast (improvised explosive device) in 45, blast (indirect fire) in seven and gunshot wound in 16 . Median length of stay was 0.92 days (IQR $0.45-2.65$ ). 82/112 admissions (73\%) were mechanically ventilated, 16/112 (14\%) required inotropic support. 12/112 (11\%) died before unit discharge. Trauma scoring was available in 65 of the 80 trauma admissions. Eight had Injury Severity Score or New Injury Severity Score $>60$, none of whom survived. However, of the 16 patients with predicted mortality $>50 \%$ by Trauma Injury Severity Score, seven survived. Seven cases required specialist advice and were discussed with the Birmingham Children's Hospital paediatric intensive care retrieval service. The mechanisms by which the Defence Medical Services support children admitted to the deployed adult ITU are described, including staff training in clinical, ethical and child protection issues, equipment, guidelines and clinical governance and rapid access to specialist advice in the UK.

Conclusions With appropriate support, it is possible to provide intensive care to children in a deployed military ITU.

\section{INTRODUCTION}

For the last 11 years, British Armed Forces have been deployed to Afghanistan with the International Security and Assistance Force (ISAF). Camp Bastion was built in Helmand Province in 2006 as the major British logistic base to support the operation and since its inception has included a Field Hospital; initially a tented facility, since 2009 the hospital has been built on hard standing. It consists of an Emergency Department (ED), Operating Theatre, Intensive Therapy Unit (ITU), currently staffed for 12 beds, and two in-patient wards. The hospital is under British management but staffed by a mixture of UK and US personnel with smaller contributions from other ISAF nations. The primary aim of the

\section{Key messages}

Paediatric casualties account for around 10\% of admissions to the deployed Intensive Therapy Unit at Camp Bastion.

- With appropriate training and support, it is possible for adult trained staff to look after critically injured children safely.

hospital is to provide medical care to ISAF personnel; however, under the Law of Armed Conflict, there is also a duty to provide medical care to the sick and injured civilians, including children, insofar as it is practicable to do so. ${ }^{1}$

It is not unusual for children to be brought to deployed Field Hospitals for medical attention in times of war. Recent conflicts have resulted in a variable proportion of child casualties requiring treatment by deployed military medical services, with published data showing children accounting for between 3\% and 18\% of hospital admissions overall. $^{2-6}$ Previous papers have described the overall paediatric workload at the Field Hospital in Camp Bastion, ${ }^{7}$ noting that around $40 \%$ of children to the hospital are admitted to the ITU at some point during their stay. Children account for around $13 \%$ of ITU admissions overall at Bastion ${ }^{8}$ and for up to $30 \%$ of ITU bed occupancy. ${ }^{9}$ This disproportionate ITU bed occupancy is because no rearward evacuation chain exists for children, whereas coalition soldiers admitted to the deployed ITU are usually evacuated within $24 \mathrm{~h}$ of admission.

Children pose a particular challenge as many members of the deployed multidisciplinary team have little specific paediatric training or expertise. Specialties represented in the Field Hospital include general, orthopaedic and plastic surgery, acute adult medicine, anaesthesia and intensive care. Although some deployed staff may have a special interest or sub-specialisation in paediatrics, there is no deployed paediatrician, nor are there currently any full time paediatricians employed by the Defence Medical Services.

The purpose of this paper is to review the paediatric workload in the deployed adult ITU at Camp Bastion following on from a previous report in $2009,{ }^{9}$ looking in more detail at injury patterns, interventions and outcomes, and at how the unit has developed to cope with the challenge of looking after critically ill children in a resource limited environment. 


\section{MATERIALS AND METHODS}

The Bastion ITU database was cross-referenced with the Joint Theatre Trauma Registry (JTTR) to identify any patient under 16 years admitted over a 1 -year period from 1 April 2011 to 1 April 2012. Data were collected prospectively on both databases. The ITU database has demographic and diagnostic data, length of ITU stay, ITU interventions, surgery, use of blood products and outcome. The JTTR contains demographic and diagnostic data, injury severity scores, ED and surgical interventions and outcome. Patients referred for advice via teleconference with Kids Intensive Care Decision Support (KIDS), the Birmingham Children's Hospital paediatric intensive care retrieval service (Birmingham, UK), were identified from the KIDS database. Statistical analysis was with SPSS (IBM, USA).

\section{Ethics}

The study was registered as an audit with the Royal Centre for Defence Medicine (RCDM/Res/Audit/1036/12/0303), which reviewed the study and waived the need for formal ethical approval.

\section{RESULTS}

Demographics, diagnosis, interventions and outcome

In the 1-year period there were 811 ITU admissions, of which $112(14 \%)$ were paediatric cases (defined as any patient under 16 years of age); 97/112 were acute admissions and 15 were readmissions of children either discharged to the ward or readmitted from other ISAF hospitals after specialist consultations. The median age was 8 years (IQR 6-12, range 1-16).

Of the 97 acute admissions, three had medical problems, one was admitted after elective surgery and the remainder were trauma (80 cases) or burns (13 cases) patients (Table 1$) ; 45 / 52$ blast injuries were due to improvised explosive devices and indirect fire such as mortar fire in seven.

Thirteen cases were burns, mostly sustained in domestic incidents, and these children were significantly younger than those presenting with other mechanisms of injury, reflecting the known epidemiology of burns in the third world. ${ }^{10}$ Burns patients also had a tendency toward higher mortality (Table 1).

The body areas affected in the 80 trauma cases were head in $21 / 80$ (26\%), face or eyes in $28 / 80$ (35\%), thorax in $9 / 80$
(11\%), abdomen in $16 / 80(20 \%)$, pelvis or genitals in $3 / 80$ $(4 \%)$ and extremities in 36/80 (45\%). Four body areas affected were in $2 / 80(3 \%)$ cases, three in $5 / 80(6 \%)$, two in $28 / 80$ (35\%) and one in 45/80 (56\%). Body area affected varied according to mechanism of injury, with gun shot wound (GSW) associated with thoracic and abdominal injury, blast with extremity and facial injuries and blunt mechanism with head injury (Figure 1). Blast injury affected significantly more body areas (median $=2$ ) than GSW or blunt injury (median=1, Kruskal-Wallis $\mathrm{p}=0.003$ ).

Median length of stay was 0.92 days (IQR $0.45-2.65$ ); 82/ 112 admissions (73\%) were mechanically ventilated and 16/112 (14\%) required inotropic support. The length of stay and ventilator days were similar across the different mechanisms of injury (Table 1) - 12/112 (11\%) died before unit discharge. Paediatric transfusion requirements were significant, with seven patients requiring more than 10 units of blood products (Figure 2). Surgical specialty input included general surgery in 65 cases, orthopaedics in 37, neurosurgery in 14, plastics in 13 and maxillofacial in four. A total of 16 patients (14\%) were transferred to other ISAF centres in Afghanistan for subspecialty input not available at Bastion, mainly to Kandahar Air Field hospital for neurosurgery, and for 12 of these patients, hospital mortality data are not available.

Trauma scores, including ISS, New Injury Severity Score (NISS) and predicted mortality from Trauma Injury Severity Score (TRISS), were available from the JTTR in 65 out of the 80 acute trauma cases. The ISS was significantly higher and NISS and TRISS had tendency to be higher in blast injury (Kruskal-Wallis $\mathrm{p}=0.016$ ) (Table 1 and Figure 3 ). None of the eight children with ISS or NISS $>60$ are known to have survived-five died at Bastion and three were transferred out for specialist care at other ISAF centres; however, of the 16 patients with predicted mortality $>50 \%$ by TRISS, seven survived.

Binary logistic regression models looking at survival in the 80 acute trauma patients (excluding patients in whom the outcome was unknown) including age, ventilation, inotropes, ITU blood product requirement and injury severity scores demonstrated that the only factor significantly associated with death were the injury severity scores (NISS, $\mathrm{p}=0.001$, ISS, $\mathrm{p}=0.017$, TRISS, $\mathrm{p}=0.005)$.

Table 1 Acute trauma admissions by mechanism of injury, $n=93$. NISS and TRISS are not appropriate for thermal injury

\begin{tabular}{|c|c|c|c|c|c|}
\hline & Blast $(n=52)$ & GSW (n=16) & Blunt ( $n=12)$ & Burn $(n=13)$ & Statistics \\
\hline Age & $8(6-12)$ & $10(7.5-12.5)$ & $9(4.75-10)$ & $5.5(3-7.75)$ & $p=0.034(K W)$ \\
\hline ISS & $22(16-32)$ & $16(9-17)$ & $10(9-13)$ & NA & $\begin{array}{l}p=0.016 \\
(K W)\end{array}$ \\
\hline NISS & $30(17-45)$ & $21(13-30)$ & $15(11-23)$ & NA & $\begin{array}{l}\text { NS } \\
\text { (KW) }\end{array}$ \\
\hline TRISS & $19.2(1.9-63)$ & $2.2(1-21.2)$ & $6.9(0.7-22.6)$ & NA & $\begin{array}{l}\text { NS } \\
\text { (KW) }\end{array}$ \\
\hline Known deaths & $5 / 52$ (9.6\%) & $2 / 16(12.5 \%)$ & $1 / 12(8.3 \%)$ & 4/13 (30.7\%) & $\begin{array}{l}\text { NS } \\
\left(\chi^{2}\right)\end{array}$ \\
\hline Body areas affected & $2(1-2)$ & $1(1-1)$ & $1(1-1)$ & NK & $\begin{array}{l}p<0.001 \\
(K W)\end{array}$ \\
\hline Length of stay & $1.1(0.3-2.6)$ & $0.8(0.5-2.8)$ & $0.6(0.3-2)$ & $0.6(2.4-0.5)$ & $\begin{array}{l}\text { NS } \\
\text { (KW) }\end{array}$ \\
\hline Ventilator days & $1(1-2)$ & $1.5(0.8-2.3)$ & $1(0-2.3)$ & $1(0-2)$ & $\begin{array}{l}\text { NS } \\
\text { (KW) }\end{array}$ \\
\hline
\end{tabular}




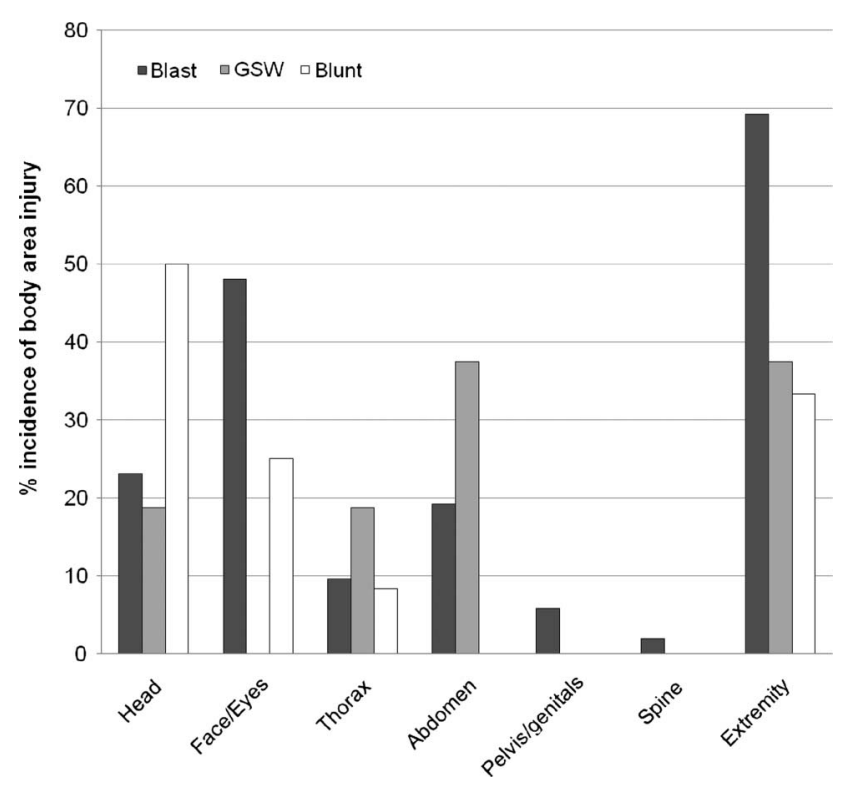

Figure 1 Incidence of body area injury according to mechanism of injury.

\section{Cases requiring specialist advice from the UK}

During the year, seven children were discussed with KIDS for specialist advice. Reasons for the call included: confirmation of present management (two cases); ethical dilemmas relating to limitation or withdrawal of life-sustaining therapy (one case); management of renal failure (one case); management of head injury (one case); subglottic stenosis (one case); and management of opiate overdose (one case). In all cases, the call advice was given by a consultant paediatric intensivist; in two cases, a further paediatric specialist from Birmingham Children's Hospital also entered the conference call. In all cases, the advice

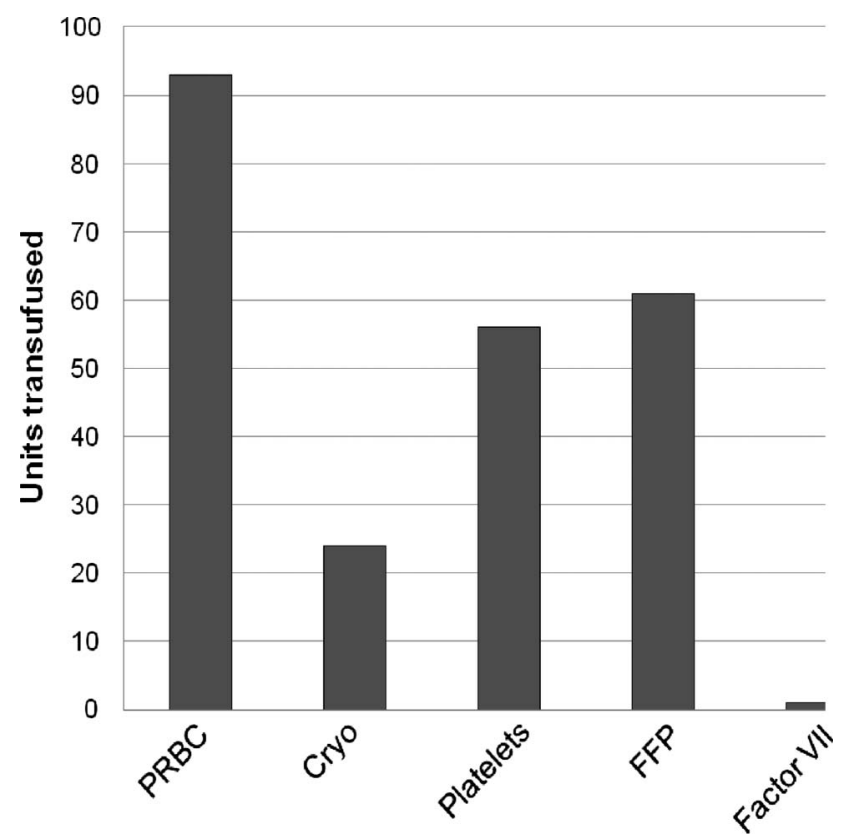

Figure 2 Utilisation of blood products (excludes products administered in Emergency Department and in Theatres). PRBC, packed red blood cells; cryo, cryoprecipitate; FFP, fresh frozen plasma; Factor VII, recombinant Factor VII. received from KIDS supported local management and was consistent with the limitations of deployed medical care.

\section{DISCUSSION}

The situation in the hospital in Camp Bastion, in which children are admitted to an adult ITU, contrasts to the UK, where after two decades of centralisation, Paediatric Intensive Care Unit (PICU) services are located in a small number of regional centres. ${ }^{11}$ Critically ill children presenting at UK centres without a PICU are usually transferred to a PICU by well resourced retrieval teams. ${ }^{12}$ As this centralisation has been associated with lower mortality, ${ }^{13}{ }^{14}$ it may be tempting for staff used to working in a developed world setting to conclude that the deployed ITU should not treat children. However, under the Law of Armed Conflict, including the Geneva Conventions, there is a duty imposed on parties involved in conflicts to provide medical care to sick and injured civilians, insofar as it is practicable to do so. This includes children.

Consequently, a number of strategies have been developed over the course of the Afghan conflict to improve paediatric care in the Field Hospital at Camp Bastion. One example of this is the development of the Paediatric Anaesthesia and Critical Care Special Interest Group (PACCSIG), a group of military critical care providers and anaesthetists with an interest in acute paediatrics, paediatric anaesthesia and paediatric critical care. PACCSIG was commissioned by the Defence Consultant Advisor in Anaesthetics and provides clinical guidelines, advice and recommendations on equipment and training. ${ }^{8} 15-17$

Furthermore, paediatric training is now provided for all staff during the pre-deployment training phase. Paediatric simulation scenarios are included in an intensive 2-week practical phase of training in the replica of the Field Hospital at the Army Medical Services Training Centre in the UK. This training, along with advanced life-support training, is compulsory for all hospital based staff. Paediatric modules and scenarios are included in the Military Operational Surgical Training course, a weeklong course attended by consultants in surgery, anaesthesia and critical care. Many medical and nursing staff also arrange short placements on PICUs to familiarise themselves with aspects of management which differ in children.

A full range of paediatric airway and vascular access equipment is available in the hospital. Recently, the ITU has acquired Vela ventilators, which have the capacity to provide ventilation of children down to $5 \mathrm{~kg}$. The Children's British National Formulary and a PICU drug calculator are available in the deployed ITU and specific drug infusion charts for children have recently been developed. Paediatric guidelines are available in the Clinical Guidelines for Operations, published by the UK Defence Medical Services, along with a variety of PICU clinical guidelines from UK centres. Military specific PICU guidelines are currently in development by PACCSIG. Specialist advice is available by telephone from KIDS, the Birmingham Children's Hospital paediatric intensive care retrieval service (Birmingham, UK). Clinical governance is devolved to the deployed Field Hospital, where there is a system of incident reporting and investigation similar to that seen in the UK.

Ethical dilemmas arise when children present with very severe injuries that may radically limit quality of life, or injuries known to have a poor outcome in the deployed environment. ${ }^{10}$ These include penetrating head trauma, severe burns or multiple injuries. Early adoption of a palliative approach may explain the tendency toward higher mortality (with short length of stay) seen in the burns patients in our series. Renal failure may also be a scenario in which palliative care is considered if recovery is not anticipated, as 

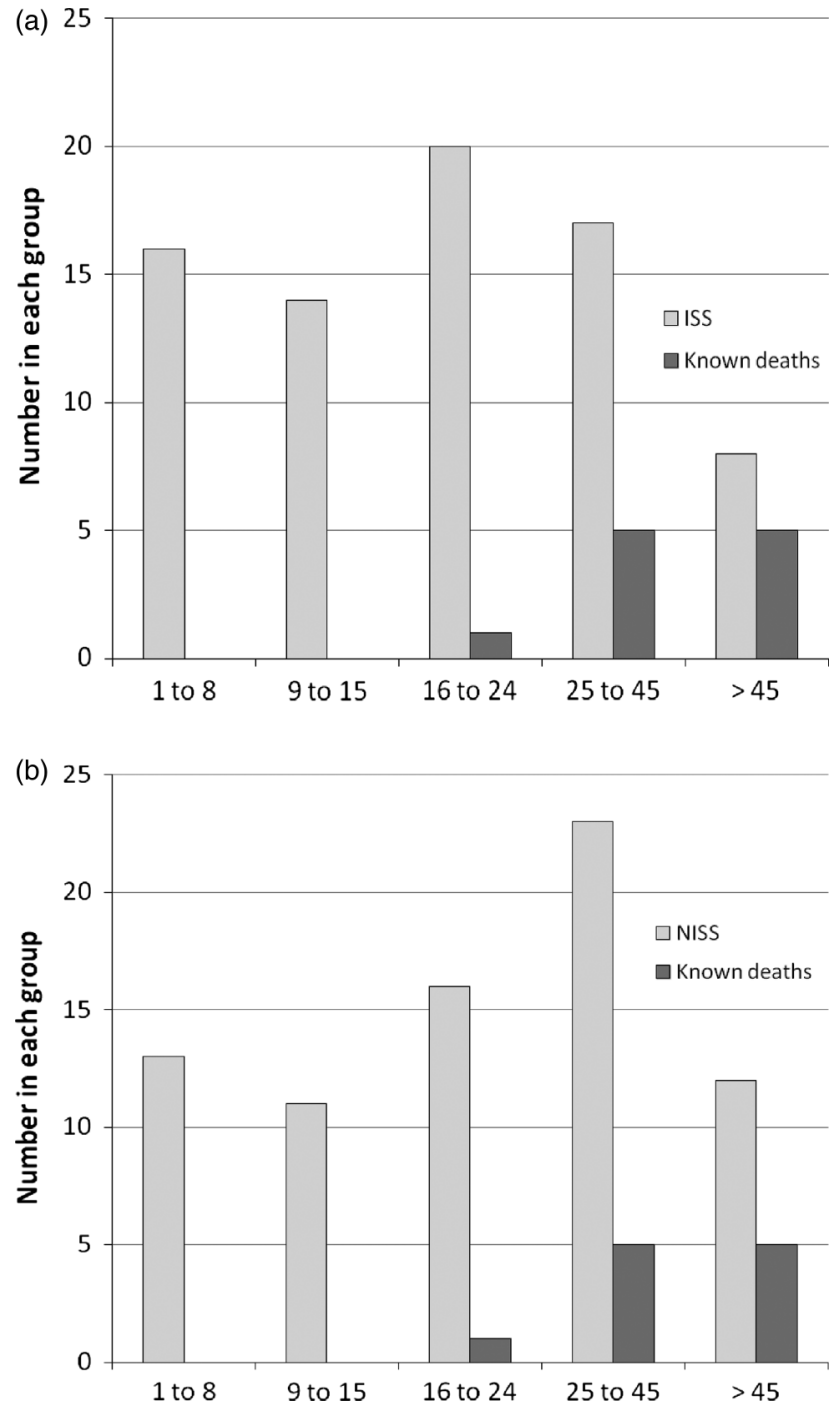

Figure 3 (A and B) Distribution of Injury Severity Scores (ISS) and New Injury Severity Scores (NISS), along with known deaths.

renal replacement therapy is not available in the deployed ITU at Bastion. While staff always try to act in the best interests of the child, sometimes these interests are difficult to assess.

Resource allocation is an immediate problem in the deployed ITU, unlike in the UK, where non-availability of critical care beds in one unit usually results in transfer of patients to other units. This possibility is not available in the deployed ITU. While the ITU has not as yet reached full capacity with local nationals, paediatric admissions could potentially create a capacity pressure. If capacity was ever exceeded this would be mitigated by discharge of patients clinically stable enough to transfer out, then allocation of resources to those most likely to benefit from treatment.

All UK based hospital medical and nursing personnel are required to undergo child protection training prior to deployment. However, as child protection services such as those seen in the developed world do not exist in Afghanistan, it is difficult to address any child protection issues which may be recognised.

Despite all these measures, dealing with critically unwell children can still be very stressful. To address this problem, for UK staff there are established systems for psychological and psychiatric support through Field Mental Health Teams on deployment and through Defence Medical Services in the UK. For UK staff, a $36 \mathrm{~h}$ decompression in Cyprus is also compulsory before returning home. Senior hospital staff are aware of the emotional impact of caring for critically injured, ill and dying children and staff informally debrief each other regularly.

The willingness with which deployed military ITU staff treat children is sometimes in contrast to civilian hospitals in the developed world, where many staff trained in adult specialties feel deskilled and may be reluctant to treat children, even in emergencies. $^{18} 19$ Our results suggest that with appropriate training and support and within a properly organised trauma system, it is possible for adult trained staff to look after critically injured children safely.

The scores, ISS, NISS and TRISS, which have been validated for paediatric use in civilian studies, ${ }^{20} 21$ were available from the JTTR for $65 / 80$ of the trauma patients. The pattern of injuries seen, the epidemiology, the proportion of high injury severity scores (with $>50 \%$ patients having ISS $>15$ ) and outcomes are similar to those documented in other recent case series from Iraq and Afghanistan. ${ }^{5}{ }^{22}$ In our study, 8 (12\%) children had ISS or NISS $>60$, none of whom survived-these deaths are all expected. However, of the 16 patients with predicted mortality $>50 \%$ by TRISS, seven survived. Such patients have previously been characterised as 'unexpected survivors', ${ }^{23}$ although clearly some might be expected to survive. There was only a single documented death in a patient with TRISS $<50 \%$ and no documented deaths in patients with ISS or NISS $<16$ (Figure 3). Binary logistic regression showed that the severity of the initial injuries was the only factor associated with death. Death was not associated with ITU interventions. Taken together, these data suggest that overall ITU performance, at least in terms of mortality, is good at Bastion.

\section{Limitations}

The overall ITU mortality at $11 \%$ is almost certainly an underestimate as it excludes deaths in transfers out to other ISAF centres, for which details were not available. Unfortunately, standardised mortality using a PICU severity of illness score such as Paediatric Index of Mortality Score 2 (PIM2) was not available, though PIM2 data are now being collected prospectively in Bastion. Although injury severity scores may provide some indication of expected mortality, these scores are not validated for patients surviving to ITU admission and were not available in all patients. Unfortunately, other markers of quality of care, including in-unit and post-discharge morbidity, were not available.

\section{CONCLUSIONS}

Previous studies of deployed military paediatric care have looked at the epidemiology of much larger numbers of children presenting to the ED. This is the first study to look in detail at the population of children admitted to ITU and to describe how the deployed adult ITU has developed strategies to deal with the challenge of looking after children. The aspiration to provide the best possible care despite the limitations is clear. This ethos along with the measures described results in adult intensive care staff delivering this care to children presenting with injuries of a severity almost never seen in the developed world. Difficult decisions regarding ongoing care will continue to be made, with staff doing their best to act in the best interests of the child, in accordance with international and military law and relevant professional guidelines.

Correction notice This article has been corrected since it was published Online First. The title of the article has been amended. 
Acknowledgements The authors thank the Academic Department of Military Emergency Medicine (ADMEM) and Defence Analytical Services and Advice (DASA) for collecting, collating and identifying the appropriate data for this paper. Dr Inwald is grateful for support from HEFCE and the NIHR Biomedical Research Centre funding scheme.

Contributors All authors contributed to the planning and reporting of the work described in the article. DPI conducted the research and wrote the first draft of the article. All authors have reviewed, contributed to and approved the article. DPI is the guarantor.

Competing interests None.

Provenance and peer review Not commissioned; externally peer reviewed.

Open Access This is an Open Access article distributed in accordance with the Creative Commons Attribution Non Commercial (CC BY-NC 3.0) license, which permits others to distribute, remix, adapt, build upon this work non-commercially, and license their derivative works on different terms, provided the original work is properly cited and the use is non-commercial. See: http://creativecommons.org/ licenses/by-nc/3.0/

\section{REFERENCES}

1 The joint service manual of the Law of Armed Conflict. Joint Service Publication 383, 2004 Edition. The Joint Doctrine \& Concepts Centre, Ministry of Defence, Shrivenham, Wiltshire, UK.

2 Heller D. Child patients in a field hospital during the 2003 Gulf conflict. J R Army Med Corps 2005;151:41-3.

3 Beitler AL, Wortmann GW, Hofmann LI, et al. Operation Enduring Freedom: the 48th Combat Support Hospital in Afghanistan. Mil Med 2006;171:189-93.

4 McGuigan R, Spinella PC, Beekley A, et al. Pediatric trauma: experience of a combat support hospital in Iraq. J Pediatr Surg 2007;42:207-10.

5 Creamer KM, Edwards MJ, Shields CH, et al. Pediatric wartime admissions to US military combat support hospitals in Afghanistan and Iraq: learning from the first 2,000 admissions. J Trauma 2009:67:762-8.

6 Borgman M, Matos Rl, Blackbourne $\mathrm{LH}$, et al. Ten years of military pediatric care in Afghanistan and Iraq. J Trauma Acute Care Surg 2012;73(6 Suppl 5):S509-13.

7 Arul GS, Reynolds J, DiRusso S, et al. Paediatric admissions to the British military hospital at Camp Bastion, Afghanistan. Ann R Coll Surg Engl 2012;94:52-7.
8 Nordmann G. Paediatric anaesthesia in Afghanistan: a review of the current experience. J R Army Med Corps 2010;156:S323-6.

9 Harris CC, McNicholas JJ. Paediatric intensive care in the field hospital. J R Army Med Corps 2009;155:157-9.

10 Dissanaike S, Rahimi M. Epidemiology of burn injuries: highlighting cultural and socio-demographic aspects. Int Rev Psychiatry 2009;21:505-11.

11 Paediatric Intensive Care Audit Network National Report 2009-2011 (published September 2012): Universities of Leeds and Leicester.

12 Ramnarayan $\mathrm{P}$, Thiru K, Parslow RC, et al. Effect of specialist retrieval teams on outcomes in children admitted to paediatric intensive care units in England and Wales: a retrospective cohort study. Lancet 2010;376:698-704.

13 Pearson G, Shann F, Barry P, et al. Should paediatric intensive care be centralised?. Trent versus Victoria. Lancet 1997;349:1213-17.

14 Pearson G, Barry $P$, Timmins $C$, et al. Changes in the profile of paediatric intensive care associated with centralisation. Intensive Care Med 2001;27: 1670-3.

15 Woods KL, Russell RJ, Bree $S$, et al. The pattern of paediatric trauma on operations. J R Army Med Corps 2012;158:34-7.

16 Bree $S$, Wood $K$, Nordmann GR, et al. The paediatric transfusion challenge on deployed operations. J R Army Med Corps 2010;156:361-4.

17 Nordmann GR, McNicholas JJ, Templeton PA, et al. Paediatric trauma management on deployment. J R Army Med Corps 2011;157:S334-43.

18 Crowe $S$, Tan K. Factors that influence stabilization times in children requiring transport. Pediatr Crit Care Med 2011;12:242-3.

19 Tomlinson A. Anaesthetists and care of the critically ill child. Anaesthesia 2003;58:309-11.

20 Sullivan T, Haider A, DiRusso SM, et al. Prediction of mortality in pediatric trauma patients: new Injury Severity Score outperforms Injury Severity Score in the severely injured. J Trauma 2003;55:1083-8.

21 Orliaguet G, Meyer P, Blanot $\mathrm{S}$, et al. Validity of applying TRISS analysis to paediatric blunt trauma patients managed in a French paediatric level 1 trauma centre. Intensive Care Med 2001;27:743-50.

22 Edwards MJ, Lustik M, Eichelberger MR, et al. Blast injury in children: an analysis from Afghanistan and Iraq, 2002-2010. J Trauma Acute Care Surg 2012;73:1278-83.

23 Russell RJ, Hodgetts TJ, McLeod J, et al. The role of trauma scoring in developing trauma clinical governance in the Defence Medical Services. Phil Trans $R$ Soc $B$ 2011:366:171-91. 